\title{
Discursos desde la catástrofe. Prensa, solidaridad y urgencia en Chile, 1906-2010
}

\section{Mauricio Onetto}

Santiago: Acto Editores, 2018. 304 páginas.

Los terremotos y sus consecuencias en el mundo y en Chile han sido trabajados en diferentes libros y artículos como Earthquakes: science and society (1999) y "Seismicity anomalies of M 5.0 earthquakes in Chile during 1964-2015" (2018). El libro que reseñamos se suma a la bibliografía que aborda esta temática, aportando con fuentes que describen los más significativos terremotos del último siglo; pero además presenta una novedosa propuesta, que contraviene las ideas de autores como Jorge Larraín en su libro Identidad Chilena (2001) y Rolando Mellafe en su artículo "El acontecer infausto en el carácter chileno: una proposición de historia de las mentalidades" (1980), en cuanto a que el fatalismo, en este caso materializado a través de los terremotos y la solidaridad, son rasgos que identifican a todo chileno.

En este libro Onetto cuestiona esta idea que ha sido transmitida en el tiempo, planteando que lejos de existir una identidad chilena, más bien lo que se da es una identificación a causa de la repetición de un acontecimiento, en este caso lo que él denomina como "catástrofes", ya que la identidad se forma a través de otros componentes, que para el autor del libro que reseñamos serían la materialidad derechos comunes, prácticas sociales igualitarias, o el respeto mutuo entre los conciudadanos. A partir de lo anterior, el fundamento central del libro es que se debe rechazar la idea identitaria creada a partir de las catástrofes, debido a que este discurso está dirigido en parte por los medios de comunicación, buscando una identificación positiva y de exclusividad para aquella historia y pueblo que la protagoniza.

Para la construcción de esta investigación el autor levanta información documental a partir de los terremotos de 1906 en Valparaíso, 1928 en Talca, 1939 en Chillán, 1960 en Valdivia, 1985 y 2010 en la zona centro-sur. Dado el nivel de destrucción producido en cada movimiento sísmico, a causa de la escasa preparación de nuestro país para afrontarlos, lo anterior conllevó la atención de la prensa local e internacional dándole una amplia cobertura a cada uno de ellos. Además, la elección de los eventos sísmicos antes mencionados tiene relación con que el autor identifica en ellos la cara más visible y representativa de las catástrofes en Chile, puesto que se repiten periódicamente y son los eventos que mayores perjuicios han provocado, 
generando un "traumatismo" (p. 14) que une las experiencias del pasado de los habitantes con su presente y las pone en tensión con el futuro.

El libro se divide en dos partes. La primera de ellas, titulada "La catástrofe desde sus discursos", se centra en el análisis de cómo los medios de comunicación han tratado la información de los sismos. Para esto se escribieron tres capítulos. El primero, "Terremotos y medios", describe cómo los medios impulsaron y ayudaron a conformar, desde las catástrofes sísmicas, determinadas nociones identitarias, relatos históricos y valores nacionales, como la solidaridad. Aquí el autor intenta probar la intervención de la prensa en temas que superan el objetivo de informar, demostrando, por ejemplo, que a pesar de las diferencias entre las consecuencias de los sismos antes mencionados, todos en su momento fueron catalogados como "catástrofes", utilizando calificativos semejantes para describirlos, esto definido por las líneas editoriales de los medios, en los que los grupos de poder confluyen para construir la lectura oficial de lo acontecido, dejando fuera a quienes se vieron afectados por los sismos, siendo todo comunicado desde la distancia.

Uno de los aportes de Onetto, que no deja de llamar la atención, es el análisis que realiza sobre la entrega de la información por parte de los medios de comunicación, en la que, a pesar del transcurrir de los años, se mantiene y replica la estructura de las noticias; por ejemplo, los primeros días se presentaban grandes titulares dando cuenta de la catástrofe, lo que en ocasiones era graficado a través de imágenes, para con el correr de los días ir desapareciendo paulatinamente entre las columnas publicadas por los periódicos, entregando información fragmentada acerca de lo ocurrido, haciendo énfasis en lugares específicos, como teatros y cementerios, y no en los efectos globales de los sismos. Asimismo, los diarios intervienen en todos los procesos de la gestión de las catástrofes, informando acerca de las actividades de ayuda, resolviendo dudas y angustias de los ciudadanos, dando a conocer las listas de las víctimas fatales y las decisiones de las autoridades por ayudar a las localidades damnificadas, lo que termina por darle a la prensa escrita la autoridad necesaria para señalar qué es lo importante para el país con el objetivo de superar la tragedia.

En esta misma línea, a juicio del autor, los diarios se han encargado de ser los promotores de las características únicas que identifican a los chilenos. Para ejemplificar aquello, el autor constata que, luego de cada terremoto, ante la destrucción nace la necesidad de reconstrucción, de resurgir y es allí donde "lo chileno" se hace presente; la resiliencia; el sobreponerse a la desgracia y al dolor mediante el esfuerzo de los chilenos y su unión, son las particularidades que supuestamente nos identifican. Para ello, el autor insiste en que la prensa se ha encargado, luego de cada movimiento telúrico, de revivir estas características, convirtiéndose en la encargada de construir la 
historia sísmica de nuestro país, evocando la historia de ciudades destruidas, otros terremotos y diferentes detalles del pasado.

Pero, ¿cómo superar la desgracia y por qué hacerlo? Pues bien, la prensa también tuvo respuesta a esta interrogante. No todo podía presentarse de manera negativa: se necesitaba buscar un equilibrio entre lo positivo y lo nefasto de la catástrofe. Para ello, en enunciados, titulares y columnas que delinean las consecuencias de los terremotos, se genera una constante valorización de la tierra, sus riquezas y bondades, y sus ciudades; se suele leer la "Perla del Pacífico" (Valparaíso), la "Perla del Maule" (Talca), la "Perla de Ñuble" (Chillán), dando a entender que los terremotos eran el precio que se debía pagar por vivir en el "Jardín del Edén".

El segundo capítulo, llamado "Solidaridad y unidad", aborda una de las supuestas características que son parte de la identidad chilena: la solidaridad, entendida por el autor como el esfuerzo de todos los chilenos por ayudarse mutuamente. Según el mismo, la prensa se levanta como el motor de la reconstrucción, tanto material como simbólica, dejando de lado en ocasiones su objetivo informativo. A través de la muestra del dolor de los afectados por los terremotos se busca motivar la ayuda, generando reacciones colectivas que incluso en la actualidad se pueden observar, como por ejemplo cuando las personas asisten en largas caravanas de vehículos y a pie a colaborar en las zonas afectadas por sismos.

Lo anterior y todas las formas de ayuda fueron descritas largamente en las páginas de los diarios, y luego, aproximadamente desde el terremoto de 1985, esto fue acompañado por la radio y la televisión, siendo una de las expresiones máximas de la solidaridad de los chilenos la campaña "Chile ayuda a Chile", en la cual surge la recordada frase del presentador de televisión Mario Kreutzberger: "cuando se trata de ayudar nadie nos gana".

Onetto desarrolla la idea de que algo ocurre con la solidaridad característica propia de los chilenos, que no logra mantenerse en el tiempo y solo se manifiesta en estados de urgencia, derribándose por tanto la idea de que los chilenos somos solidarios, ya que esta unión, que busca ir en ayuda de las personas damnificadas por catástrofes, solo aparece en situaciones de urgencia, y además esconde en el fondo una ilusión igualitaria para maquillar la desigualdad social de nuestro país, labor que fue ejercida por la prensa, siendo los mayores reproductores de los discursos de la solidaridad chilena. El autor sostiene que de ello se aprovechó la clase política, que vio en la desgracia producida por los terremotos una posibilidad de mostrarse cercana al común de las personas a través de un espíritu solidario, conciliando asperezas y llegando a acuerdos, momento propicio para que las autoridades crearan e impusieran nuevas leyes. 
Asimismo, sostiene el autor que de la solidaridad también se han aprovechado las empresas. El libro señala que antiguamente eran los gremios, los sindicatos y las organizaciones sociales quienes representaban al comercio, pero paulatinamente esto fue cambiando. Las catástrofes se utilizan ahora para promover productos elaborados por las grandes empresas, las cuales además aprovechan de mostrar una imagen positiva de sí mismas, compitiendo entre ellas para apropiarse del discurso de solidaridad. La publicidad de las empresas se reprodujo sin pausa y asumió una responsabilidad social, todo gracias a su control de los medios, pasando de ser colaboradores anónimos a protagonistas activos, logrando los empresarios apropiarse de la solidaridad.

Finalmente, en cuanto a la solidaridad, la prensa intentó conectar las muestras de ayuda internacional con la unidad interna. Los medios de comunicación recordaban cada vez que podían que el resto del mundo estaba observando a Chile y su forma de superar las catástrofes. Y esto también se vincula con la idea de que nuestro país ha luchado desde su origen con la idea del olvido y el abandono, al ser el "último bastión" de la tierra. Por lo tanto, existen ansias de ser considerados y de valorizar la solidaridad, incluso omitiendo la realidad política internacional, por ejemplo, cuando se recibieron donativos de los nacionalistas españoles en medio de la Guerra Civil.

El tercer capítulo, denominado "Efectos y disyuntivas de los discursos", aborda los efectos de los discursos de la prensa sobre las catástrofes, en los que, además de los ya mencionados sentimientos de solidaridad y unión entre chilenos, destaca la valorización de los símbolos patrios. Para lograr lo anterior, el autor plantea que los medios se encargaron de atacar toda ofensiva en contra de lo nacional, lo que fuera en contra del "espíritu chileno" era abiertamente criticado, como por ejemplo los robos luego de cada catástrofe, siendo uno de los recuerdos más vívidos los saqueos producidos en Concepción luego del terremoto del 27 de febrero de 2010. Cuando estas situaciones de desórdenes aparecían, la primera reacción fue la militarización de las zonas devastadas, lo cual era avalado por la prensa, siendo la única forma de normar ante lo excepcional; los discursos que emergieron desde la urgencia, relacionados con la solidaridad y la unidad, encubrían cualquier tipo de cuestionamiento hacia las decisiones tomadas por las autoridades. Todo lo anterior ha encubierto no solo las decisiones del Estado, sino que también la falta de cuestionamiento en cuanto a vivir en un suelo telúrico, lo que ha provocado la forma descoordinada y discontinua de la edificación en Chile: cada quien decide cómo y dónde construir según sus necesidades, dejando de lado la reflexión y la búsqueda de soluciones en el largo plazo, no actuando según nuestra experiencia en el tiempo.

La segunda parte de esta investigación lleva por nombre "Desde el poder, la catástrofe", y corresponde es una selección de fuentes en las que hay cartas al director, notas de prensa, columnas, telégrafos, entre otros, 
que fueron pieza fundamental para la construcción de los argumentos presentados por el autor.

Discursos desde la catástrofe es un libro que, a lo largo de sus páginas, nos hace replantear la forma de analizar y utilizar las fuentes para la construcción de una investigación, además de tensionar la clásica idea de que la catástrofe como fenómeno histórico y cultural, ha penetrado en la identidad chilena. Onetto devela aquello dando a entender los factores históricos que la movilizaron y cómo, a pesar de la modernidad en los medios de comunicación, estos han continuado con un relato prácticamente similar. Es por todo lo anterior, que esta obra es admirable, puesto que confronta, mediante un acabado análisis de fuentes, ideas que parecen haber sido aceptadas por la mayoría de las personas. Además, es un libro de fácil lectura, comprensible para los diversos públicos a los que llegue, siendo una obra totalmente recomendable.

Pablo Moya Rojas ${ }^{1}$

\section{Referencias bibliográficas}

Adagunodo, T. et al. (2018). "Seismicity anomalies of m 5.0+ earthquakes in Chile during 1964-2015", en Journal of Tsunami Society International, Vol. 38, No 2, pp. 130-156.

Mellafe, R. (1981) "El acontecer infausto en el carácter chileno: una proposición de historia de las mentalidades", en Atenea, № 442, octubre 1981, pp. 121-128.

Brumbaugh, D. S. (1999). Earthquakes: science and society. New York: Prentice Hall.

Larraín, J. (2001). Identidad chilena. Santiago: LOM Editores.

Chileno. Profesor de Historia y Geografía, Universidad San Sebastián, Chile. Magister en Educación Inclusiva, Universidad Central, Chile. Encargado de Educación y Extensión, Archivo Nacional Histórico de Chile. E-mail: pablo.moya@archivonacional.gob.cl 